\title{
The Extinction of Fire with Plain Water: A Review
}

\author{
D. J. RASBASH
}

University of Edinburgh, Unit of Fire Safety Engineering

Edinburgh, EH9 3JL, United Kingdom

\section{ABSTRACT}

Research into the extinction of fire of solid and liquid fuels by plain water has been reviewed. Properties of water sprays and of the fires themselves that influence the performance of sprays as extinguishing agents are outlined. The results of basic investigations which have yielded data which are of assistance to quantifying extinction processes and of empirical investigations designed to provide information directly applicable to practical problems have been briefly summarised. Simple quantitative approaches to two forms of extinction for which basic data exists i.e. extinction of the flames by spray and cooling the fuel to the firepoint are outlined. The approach to extinction by cooling also points to an approach for deciding under which conditions stable flaming may be formed on the whole of a fuel surface in the absence of spray. Areas for future research are indicated.

\section{INTRODUCTION}

Fire and the way it is affected by water in the form of rain is a force that has helped fashion the very nature of our living environment. It is probably safe to say that since mankind first made use of fire, they made use of water to control it. Apart from rhetorical quotations, very little has come down to us from these aeons of time, on just how much water is needed to control fires of different kinds. It has undoubtedly long been found useful to have a few buckets of water to hand since they are very good at extinguishing fires before they become really dangerous. Apart from this there has been the tendency, for some fire authorities to base demands for waters supplies on instinct, with an eye perhaps more on what can be made available rather than what might be really needed.

Water although nominally quite cheap in most places, becomes quite expensive if it has to be handled and stored in large quantities for emergency purposes. The important practical problem also exists of making the best out of limited supplies of water that may be available in the early stages of fires of all kinds. These demands call for a fund of structured information on the subject. A significant amount of research has been carried out which has gone some way to filling this gap. It is the aim of this paper to summarise this information, to point to where coherent patterns lie within it, and to indicate where scope lies for further work. 


\section{HEAT ABSORPTION PROPERTIES OF WATER}

The major useful property of water as an extinguishing agent is its capacity to cool burning fuels to a temperature below which they cease to burn. In general this capacity substantially exceeds that of other extinguishing agents, including carbon dioxide and nitrogen, as indicated in table 1. The exception is the inability of water to cool fuels that can burn near or below normal ambient temperatures, particularly low flash point liquids like gasoline.

TABLE 1 - Maximum cooling capacity of water and other agents for extinction processes, expressed as $\mathrm{J} / \mathrm{g}$ agent.

\begin{tabular}{|c|c|c|c|c|c|}
\hline \multirow[t]{2}{*}{ Agent } & \multirow{2}{*}{$\begin{array}{l}\text { Agent } \\
\text { temperature }\end{array}$} & \multicolumn{2}{|c|}{$\begin{array}{l}\text { Enthalpy change rele-- } \\
\text { vant to cooling } \\
\text { solid and liquid } \\
\text { fuels to: }\end{array}$} & \multicolumn{2}{|c|}{$\begin{array}{l}\text { Enthalpy change rele- } \\
\text { vant to cooling } \\
\text { reaction zone in } \\
\text { flames to } 1300^{\circ} \mathrm{C}\end{array}$} \\
\hline & & $100^{\circ} \mathrm{C}$ & $250^{\circ} \mathrm{C}$ & $\begin{array}{l}\text { In gas phase } \\
\text { and condensed } \\
\text { phase }\end{array}$ & $\begin{array}{c}\text { In gas phase } \\
\text { alone }\end{array}$ \\
\hline Water & 15 & 2612 & 2900 & 5317 & 2704 \\
\hline $\begin{array}{l}\text { Carbon dioxide } \\
\text { (solid) }\end{array}$ & -78 & 637 & 872 & 2158 & 1585 \\
\hline $\begin{array}{l}\text { Nitrogen } \\
\text { (1iquid) }\end{array}$ & -196 & 405 & 652 & 1885 & 1685 \\
\hline
\end{tabular}

\section{RELEVANT PROPERTIES OF JETS, SPRAYS AND FIRES}

Water is normally applied to a fire in the form of a jet or a spray. A jet allows the water to reach the fire area more easily, but has a very limited capacity for rapid removal of heat whereas a spray can remove heat rapidly. However when a jet reaches a solid surface it can break up into a spray or form a film of water over the surface which improves its capacity to remove heat. It can also be moved manually to similar effect.

The reach of a jet depends on the pressure and the flow rate at the nozzle and its angle of elevation. It also depends on the nozzle design. Recent improvements in nozzle design have led to a significant increase in the throw of jets (1). The reach of sprays depends also on the cone angle of the spray; for a given pressure and flow rate, its reach is substantially less than a jet. The following formula for the throw $z(m)$ of sprays was arrived at by regression analysis (2).

$\mathrm{Z}=1.1 \mathrm{~F}^{0.36} \mathrm{P}^{0.28} /(\tan \theta / 4)^{0.57}$

$\mathrm{F}=$ flow rate $(0.7-331 / \mathrm{s})$

$\mathrm{P}=$ nozzle pressure (3-11 bar)

$\theta=$ cone angle $\left(30^{\circ}-90^{\circ}\right)$

The following properties of water sprays have been found relevant to their action on fires. 
1. Mean flow rate per unit area in the region of the fire.

2. Distribution of the flow rate at and about the fire area.

3. Direction of application towards the fire area, particularly whether the spray is being applied downwards against the flow or with a substantial. sideways component.

4. Drop size of the spray and drop size distribution.

5. The velocity of the current of air entrained by the spray.

6. The velocity of the drops related to (a) the entrained air current, (b) the flame the drops move through, and (c) the fuel which is impacted.

The size and velocity of the spray drops mainly affects the heat transfer to flame and fuel but they also affect the tendency of drops to enhance the burning rates of liquids by causing splashing and sputtering at the fuel surface. Also together with the entrained air current they control the ability of the spray drops to penetrate an upward moving flame. All practical sprays have a wide distribution of drop size and care has to be exercised in deciding on the relevant representative drop size to use since drop size enters into the physical laws that influence the effects of sprays on fires in widely different ways. In this paper the mass or volume median drop size will be used as a representative drop size. In general, it lies between the "volume mean" drop size ( $\Sigma$ nd $/$ snd $^{3}$ ) and the "area mean" or Sauter Mean drop size ( $\Sigma n^{3} /$ End"). However the "mean volume" drop size $\left(\sqrt[3]{\frac{\sum_{n} d^{3}}{\Sigma n}}\right)$ which is considerably
smalier, has also been used by some workers.

The nature of a fire also has an influence on the ease with which water can extinguish it. The temperature at which the fuel may and does burn, the geometrical distribution of the fuel surfaces and the thermal properties of the fuel and any char that forms are, of course, major influences. The size and upward velocity of the flames as well as their temperature and intensity of combustion influence the ease with which the flame may be extinguished and the ability of the spray to reach the fuel.

There follows a sumnary of research investigations of the extinction of fire with plain water. These will be divided into two areas; basic research when a quantitative approach to interpreting the results is aimed at, and empirical full scale tests.

\section{BASIC RESEARCH ON EXTINCTION OF FIRE}

Liquid Fires. Work by the author in the 1950's in which the majority of the above factors were monitored revealed the complexity of the interaction between sprays and liquid fires. The work was carried out with two forms of apparatus:

(a) Sprays of a range of drop size $(0.2-2.0 \mathrm{~mm})$ produced from a battery of hypodermic needles, were allowed to fall at different rates onto a kerosine fire $11 \mathrm{~cm}$ diameter, situated $120 \mathrm{~cm}$ below the battery. The object of the hypodermic needles was to obtain sprays of uniform drop size ( 3 ). This was reasonably successful for drop sizes greater than $0.6 \mathrm{~mm}$.

(b) Sprays of a range of drop size and flow rate produced at different pressures from batteries of pairs of impinging jets projected downwards on fires burning in a vessel $30 \mathrm{~cm}$ diameter $175 \mathrm{~cm}$ below the jets. Most tests were carried out on a $6 \mathrm{~cm}$ deep layer of burning kerosine or gasoline but other liquids were used as well $(4,5)$. 
The main observations in the tests were:

1. If the kerosine fire was not extinguished, it stabilised in a few minutes after application of the spray with a temperature near the surface which was usually lower, and a flame size and mean rate of burning which was usually less than the values obtained in tests without spraying. The temperature distribution within the fuel layer was also made more uniform. These results are exemplified in figures $1 a, b, c$ and $d$.

2. There was a most effective drop size for the kerosine fire for reducing burning rate and cooling the fuel, which in series (a) was $0.4 \mathrm{~mm}$ and in series (b) decreased from $0.7 \mathrm{~mm}$ to $0.35 \mathrm{~mm}$ as the pressure at the spray battery increased from 0.35 bar to 2.1 bar. At the most effective drop size $40-50 \%$ of the spray penetrated to below the burning fuel. Minimum stable burning rates occurred at this drop size, which were about $2-3$ $\mathrm{g} / \mathrm{m}^{2} \mathrm{~s}$, compared with $10 \mathrm{~g} / \mathrm{m}^{2} \mathrm{~s}$ and $14 \mathrm{~g} / \mathrm{m}^{2} \mathrm{~s}$ for the (a) and (b) fires respectively. At coarser drop sizes (more than 1.7 times most effective drop size) a considerable amount of splashing of the fuel into the flames took place, at finer drop sizes (less than about 0.7 of most effective drop size) only some $10-20 \%$ of water penetrated the fuel layer, and fuel was sputtered into the flame by the fine drops evaporating as they hit the hot kerosine. Both these mechanisms increased the burning rate. For series (b) it was possible to correlate the downward thrust of the entrained air stream, the drop size and the fraction of spray that penetrated the flame (6).

3. The kerosine fire was extinguished in two distinct ways:-

(a) by cooling the liquid temperature to the neighbourhood of the fire point as measured by the cleveland open cup $\left(58-68^{\circ} \mathrm{C}\right)$. In this case the flames reduced to a small size before extinction and reignition did not take place immediately on the application of an ignition source following extinction. The flow rates of water required to bring about extinction increased from $100 \mathrm{~g} / \mathrm{m}^{2} \mathrm{~s}$ to $300 \mathrm{~g} / \mathrm{m}^{2} \mathrm{~s}$ as the drop size increased from $0.4 \mathrm{~mm}$ to $1.2 \mathrm{~mm}$. The closed cup flash points of the unburned kerosines used were in the range $40-45^{\circ} \mathrm{C}$.

(b) the flame was itself extinguished when of substantial size. The fuel surface temperature at extinction was well in excess of the fire point. Usually substantial momemtary partial clearance of flame took place prior to extinction. After extinction application of an ignition source brought about immediate reignition. Extinction times were usually much shorter than when the liquid was cooled to the fire point.

4. The gasoline fire was only extinguished by the second of the above mechanisms. At a spray pressure of 5.9 bar, extinction did not take place at a drop size greater than $0.6 \mathrm{~mm}$ nor a flow rate less than $130 \mathrm{~g} / \mathrm{m}^{2} \mathrm{~s}$. As long as the spray could penetrate the flames in sufficient quantity the extinction time was proportional to the fourth power of the drop size and inversely to the second power of the flow rate (4).

5. Certain sprays which could extinguish the gasoline fires readily (2-12 seconds extinction time) when the preburn time (i.e. time between ignition and spray application) was 15 seconds or more, could not extinguish the fire when the preburn time was less than 10 seconds. The spray caused the flames to be pushed into a horizontal shape burning in the entrained air of the spray. A similar phenomenon occurred with benzole fire. With the kerosine fire this phenomenon would give extinction by cooling to the fire point but in a much longer time. As a result for a given spray acting on a kerosine fire a bimodal distriubtion of extinction times as a function of preburn times occurred (4). 

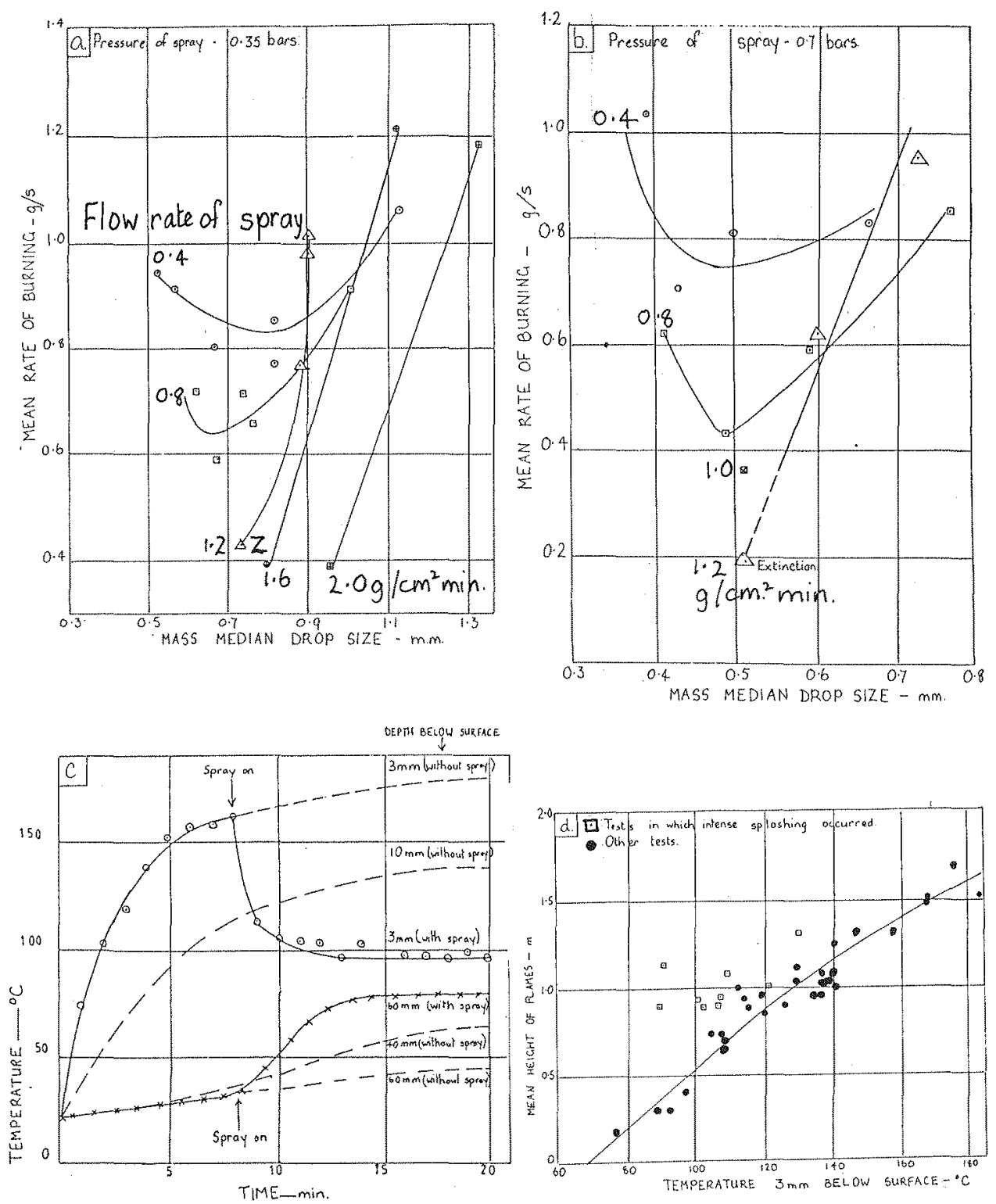

Fig. 1 - Effect of water sprays on a kerosine fire. Properties of fire: $300 \mathrm{~mm}$ diameter, $20 \mathrm{~mm}$ ullage, burning rate $1.0 \mathrm{~g} / \mathrm{s}$. (a) and (b) Effect of spray flow rate and dropsize on burning rate, (c) Effect of a spray ( $Z$ in (a)) on temperature below kerosine surface, (d) Relation between flame height and temperature $3 \mathrm{~mm}$ below surface. 
6. For sprays of flow rate $267 \mathrm{~g} / \mathrm{m}^{2} \mathrm{~s}$ and drop size $0.28 \mathrm{~mm}, 0.38 \mathrm{~mm}, 0.49 \mathrm{~mm}$ and fires in diesel oil (fire point $104-115^{\circ} \mathrm{C}$ ) and transformer oil (fire point $175-180^{\circ} \mathrm{C}$ ) there was a large upsurge of flame in the first $1-2$ seconds. They nevertheless were usually extinguished a few seconds later and more quickly than a kerosine fire. The coarser spray was rather more effective than the finer spray. The two coarser sprays extinguished an alcohol fire by diluting the surface layers but the finest spray extinguished the flames of this fire in a few seconds.

Solid Fires. As long as the water flow can reach the surfaces of the burning fuel then flow rates of the order of only a few $\mathrm{g} / \mathrm{m}^{2} \mathrm{~s}$ have been found capable of extinguishing many solid fires. Moreover the flow rate needed is not particularly sensitive to the drop size of the spray. Thus Bryan (7) used a moving jet of water to extinguish a rotating crib fire. The minimum flow rate for extinction in his experiments was about $1.6 \mathrm{~g} / \mathrm{m}^{2} \mathrm{~s}$. Magee and Reitz (8) applied water. spray to vertical and horizontal burning plastic materials, exposed to different levels of radiation up to $11 \mathrm{KW} / \mathrm{m}^{2}$. Table 2 gives critical water flow rates for extinction when there was no external radiation. For delrin and PMMA the heat of vaporisation of the extra water flow needed when the sample was exposed to external radiation balanced the external radiation.

TABLE 2 - Critical water flow rates for extinction with water spray. After Magee and Reitz. (No external radiation)

\begin{tabular}{lcl} 
Polymer & $\begin{array}{c}\text { Surface vertical } \\
\mathrm{g} / \mathrm{m}^{2} \mathrm{~s}\end{array}$ & $\begin{array}{c}\text { Surface Horizontal } \\
\mathrm{g} / \mathrm{m}^{2} \mathrm{~s}\end{array}$ \\
\hline PMMA & $<2.7(\sim 1.7)$ & $<1.7(\sim 1.3)$ \\
DELRIN & 1.9 & $<2.7(\sim 2.0)$ \\
PS & & $<4.1(\sim 3.0)$ \\
PE & & $<6.0(\sim 4.3)$ \\
\hline
\end{tabular}

TABLE 3 - Critical fuel flow rates at extinction with water spray; after Magee and Reitz. Radiation $0-0.4 \mathrm{cal} . / \mathrm{cm}^{2} \mathrm{~s}$. Various water flow rates.

$$
\begin{array}{cc}
\text { Surface Vertical } & \text { Surface Horizontal } \\
\mathrm{g} / \mathrm{m}^{2} \mathrm{~s} & \mathrm{~g} / \mathrm{m}^{2} \mathrm{~s}
\end{array}
$$

$\begin{array}{lcc}\text { PMMA } & 3.4 m-4.0 & 6.0 \\ \text { DELRIN } & 6 & 4-5.5 \\ \text { PS } & & 9 \\ \text { PE } & & 11\end{array}$

This suggests that water is capable of being more or less completely vaporised at a solid burning surface. However, for polystyrene and polyethylene rather higher flow rates were required in the absence of external radiation. Moreover the extra flow needed for the irradiated sample was more than would balance the extra radiation. When water spray was applied to these two polymers fuel was sputtered into the flame. This is indicated in Table 3, which gives the critical flow rates of fuel at extinction with water spray, indicating substantially higher flow rates for these than for delrin or for PMMA. With the former materials a coarse spray was found to be more effective than a 
finer one. The measured fire point of polystyrene is $350^{\circ} \mathrm{C}$ and polyethylene $330^{\circ} \mathrm{C}(9)$, whereas the melting points are $240^{\circ} \mathrm{C}$ and $138^{\circ} \mathrm{C}(10)$. Thus a horizontal surface of these materials would be covered by a significant layer of very hot liquid. A vertical surface would burn as a running liquid fire.

It is characteristic of solid fires that burning surfaces may be obscured to a varying extent from the direct action of the spray i.e. there is obstruction. A review carried out by Heskestad (11), indicated a range of critical flow rates per unit area for wood in various geometrical forms from slabs to cribs varying from 1.3 to $3.0 \mathrm{~g} / \mathrm{m}^{2} \mathrm{~s}$; the higher rates seemed to apply to the more densely packed cribs. Of course the total exposed fuel surface area on which burning takes place in a crib may substantially exceed the plan area of the fuel. Experiments were carried out by 0 !Dogherty et al (12), in which the spray was applied downwards to fire in cribs of the order of $0.9 \mathrm{~m}$ wide and $1 \mathrm{~m}$ deep, made up of $2.5 \mathrm{~cm}$ sticks and with a total exposed stick area of about $48 \mathrm{~m}^{2} / \mathrm{m}^{2}$ of top surface. These indicated that as long as the flames were beaten down to allow water spray to reach the burning fuel, then a flow rate of $187 \mathrm{~g} / \mathrm{m}^{2} \mathrm{~s}$ reaching the top surface of the crib, could extinguish the fire in about 10 minutes. This corresponds to about $4 \mathrm{~g} / \mathrm{m}^{2}$ of fuel surface area per second. O'Dogherty also developed a standard test for extinguishers using wood cribs of varying lengths (13). His results indicate that an extinguisher delivering about $6 \mathrm{~g} / \mathrm{m}^{2} \mathrm{~s}$ could extinguish a fairly open crib fire in about 1 minute; comparing this with information in ref.7, suggests a critical rate of about $2.5 \mathrm{~g} / \mathrm{m}^{2} \mathrm{~s}$.

Bhagat (14) found however that to extinguish glowing charcoal with spray of drop size $60-120 \mu$ carried in an air stream at $10.4 \mathrm{~m} / \mathrm{s}$ a flow rate of about $10 \mathrm{~g} / \mathrm{m}^{2} \mathrm{~s}$ was needed. Lower flow rates tended to increase the burning rate of the charcoal above what they were without spray by removing ash from the surface.

\section{QUANTITATIVE APPROACH TO EXTINCTION}

The experiments on liquid fires show that extinction can occur either by extinction of flame or cooling the fuel. Evidence in the experiments on fire in solids, particularly the balancing of extra radiation with extra water flow needed, indicates also that cooling the fuel is the major aspect of extinction of these fires. Actually it will be seen in the discussion below that extinction by cooling the fuel is a special case of extinction of the flame.

Extinction of the Flames. It has been found that the amount of diluents such as nitrogen, carbon dioxide or water vapour needed to extinguish premixed flames is sufficient to reduce the adiabatic flame temperature to about that of the lower flammability limit. Indeed this limit may be regarded to arise from diluting the flame with air (oxygen and nitrogen) above that which is needed for combustion. A lower limit adiabatic flame temperature of about $1580 \mathrm{~K}$ or $1300^{\circ} \mathrm{C}$ emerges for most hydrocarbons and other organic vapours, from these considerations. This may be regarded as a minimum temperature where a sufficient rate of reaction can be sustained in the limit flame relevant to the particular aerodynamic conditions under which the flame is propagating. The ratio of lower limit concentration to stolchiometric concentration for the vapours concerned is between 50-60\%; the extra diluent is therefore responsible for absorbing about $45 \%$ of the heat of combustion at the limit temperature. It may be argued therefore that any heat transfer mechanism and particularly heat transfer between spray drops and flames which may be responsible for absorbing this fraction of the heat of combustion from the reaction zone should prevent the flame propagating. Table 1 also indicates that if all the heat transfer results in steam, the heat absorption needed to bring about extinction could be halved. 
Experiments with diffusion flames have indicated that these flames are often extinguished with a lesser requirement of diluent than premixed flames (15). Thus 30 and $60 \mathrm{~cm}$ diameter diesel oil fires were found to be extinguished when burning in a diluent gas based mainly on water vapour and nitrogen when the oxygen concentration was $14.5-15 \%$, whereas the composition of the gas was such as to indicate that a reduction to $12.2 \%$ would be needed to prevent flame propagation in a premixed gas. Flame on a wick (dimension about 5mm) was extinguished at a concentration of $16.7 \% 0$, A flame about $3 \mathrm{~cm}$ wide and $10 \mathrm{~cm}$ long travelling vertically up a group of thin wooden sticks was extinguished with $13.2 \%$ of oxygen in nitrogen, whereas flame propagation through premixed vapours was estimated as requiring a reduction to $11.3 \%$. The implication is that for diffusion flames of dimension $5-60 \mathrm{~cm}$, removal of about $30-35 \%$ of the heat of combustion from within the reaction zone would cause the flame to be extinguished. The probable reason is that the diffusion flames near extinction are losing substantialily more heat by radiation from the reaction zone than premixed flame near the limit and also combustion is less complete. The latter would certainly be implied by the existence of luminous, thus sooty flames prior to extinction. A very small flame required a heat removal factor of only about 0.2 for extinction and there may be a partial blow out effect associated with this small value.

It was found that for the $30 \mathrm{~cm}$ diameter liquid fuel fires tested with sprays, the intensity of combustion in the flames without spray was about $2 \mathrm{~W} / \mathrm{cm}^{3}$ and independent of the fuel. The mean temperatures across the flames were measured as $921^{\circ} \mathrm{C}$ (benzole to $1218^{\circ} \mathrm{C}$ (alcohol). While these are less than the $1300^{\circ} \mathrm{C}$ limit temperature mentioned above, it must be remembered that there was a substantial unmixedness factor for the turbulent flames concerned, these being non-uniform mixtures of unburned fuel vapours, unburned air, reaction zone and combustion products. Proceeding on the assumption that the capability of the spray to cool any of these items will contribute to the cooling of the reaction zone, indicates that there may be a correlation between the capability of the sprays to extract heat from the flames and the extinction of the flame. This was examined (16) and found to be the case. For extinction of the flame to take place it was found that the spray when entering the flame needed to have an ability to extract 0.4 of the heat produced in unit volume of fllame. The downward force of the spray also needed to be greater than about 0.7 of the upward force of the flames, presumably to allow water spray to enter the lower parts of the spray, but one could argue that the downward entrained air current was forcing combustion products back into the flame. The difficulty in extinguishing flames when the preburn time was less than 10 seconds was probably caused by flames being made to burn stably but more intensely in the air current of the spray, as a horizontal sheet above the fuel surface.

Cooling the Fuel. The concept of the fire point is that it is the minimum fuel temperature at which a stable flame may be formed across the whole surface of the fuel. The observations of flame size as fire point conditions are approached (Fig. 1d) suggest that, apart from intense splash fires, heat transfer is probably dominated by convection from the flame which will approach a maximum at the fire point, rather than by radiation. It is possible for fuel surfaces to maintain continuous flashing flames at temperatures below the fire point if vapours evolved can produce concentrations within the limits and at thicknesses greater than about half the relevant quenching distance. However, heat transfer to the fuel will be significantly less than at the fire point, since at any instant only part of the surface is covered by flame. Moreover such flames are very vulnerable to wind and the entrained current of sprays. They are unlikely to be of importance during extinction with water sprays. 
The author has approached extinction, by cooling the fuel on the basis of a heat balance at the fuel surface with separation of convective and radiant heat transfer $(6,17,18,19)$. The spray will cool the fuel if it can cause removal of sensible heat from the surface at a rate per unit area $\mathrm{S}$ given by:

$S=\left(H_{f}-\lambda_{f}\right) \dot{m}^{\prime \prime}+R_{a}-R_{s}$

$\dot{\mathrm{m}}^{\prime \prime}$ = rate of burning per unit area

$\mathrm{H}_{\mathrm{f}}=$ convective heat transfer from flames associated with unit mass of fuel entering the flame

$\lambda_{f}=$ heat imparted to the body of the fuel which is necessarily associated with the production of unit mass of fuel vapour; under steady state conditions this may be equated to the heat required to produce the volatiles,

$R_{a}=$ other forms of heat transfer to unit area of fuel surface including radiation from the flames, from the outside environment, and by conduction from hot metal etc.

$\mathrm{R}_{\mathrm{s}}=$ heat loss from surface not included in $\lambda_{\mathrm{f}}$ especially heat loss by radiation.

To cool the fuel to its fire point, the spray has to be capable of removing heat at the relevant rate $S$ throughout the whole cooling process from application of spray to the fire point. The capacity of water spray to remove heat from the fuel may remain relatively constant for a solid fire but could for a kerosine fire be lowered significantly as the temperature of the fuel is reduced. As the fuel is cooled the contribution of radiation from the flames to $R_{\text {a }}$ will be reduced since a reduction of $\dot{m}^{\prime \prime}$ will cause a reduction in flame size (Fig. 1d). However the convective heat transfer H $\dot{m}^{\prime \prime}$ will increase somewhat because of the reduction of the blocking effect caused by reduced fuel vapour flow. Extinction by cooling will be expected to occur if the cooling rate is greater than $S$ throughout the cooling process and at the special condition at the fire point as well as covered by equation 2 .

$O>\left(H_{f c}-\lambda_{f}\right) \dot{m}^{\prime \prime} c+R_{a c}-R_{s c}-S_{c}$

The subscript $c$ in equation 2 implies conditions at the fire point. $H$ is a maximum value of $H_{f}$ and may be expressed as a fraction $\varnothing$ of the heat of combustion $\mathrm{H}$. Also $\mathrm{f}_{f}$ and $\mathrm{m}^{\prime \prime}$ may be related, and as the fire point condition approaches, $\mathrm{H}_{\mathrm{f}}$ and $\mathrm{m}^{\prime \prime}$ may perhaps more tentatively be related, through Spalding's $\mathrm{B}$ number $(20)^{\mathrm{C}}$ as follows:-

$m^{\prime \prime}=f\left(\varnothing, H, m_{o g}, T_{g}, T_{s}, h, c\right.$ etc. $) \approx \frac{h}{c} \ln \left(1+\frac{A}{\phi H}\right)$

$\mathrm{A}=\mathrm{m}_{\mathrm{og}} \mathrm{H} / \mathrm{r}+\mathrm{C}\left(\mathrm{T}_{\mathrm{g}}-\mathrm{T}_{\mathrm{S}}\right) ; \mathrm{A} / \phi \mathrm{H}=\mathrm{B}$ number at the fire point

Equation 3 may also be taken as a condition for establishing a stable flame that covers the whole surface area of the fuel.

As indicated above small flames were noted as the fire point condition was approached. Moreover there is a lack of sensitivity to fire size of critical flow rates for extinction by cooling of liquid fires for pools of diameter 0.11 to $2.43 \mathrm{~m}$ (6). These observations provide some justification for ignoring radiation from the flame to the surface, as a factor influencing critical flow rates needed for extinction by cooling. Experiments by Spalding (20) on cooling kerosine fires on a small sphere with excess fuel and 
other experiments indicate that $\varnothing$ is about $0.2-0.4$ for normal organic fuels of composition ranging between hydrocarbons - cellulosics, when burning in air at ambient temperatures, a mean value of 0.3 for $\varnothing$ has been suggested (17). This may be compared with a heat removal factor of about 0.33 for large radiant diffusion flames and 0.45 for premixed propagation flame. Estimates that then may be made using equation 2 of rate of burning under fire point conditions, and water flow rate requirements. are reasonably in agreement with rates mentioned above for kerosine, wood and PMMA. The equation however cannot cover conditions of intense sputtering or splashing.

Equations (2) and (3) do not explicitly take account of the influence that the flow of water vapour $\left(\dot{m}^{\prime \prime}\right)$ produced at the fuel surface may be having on cooling the flame. This is unlikely to have a major effect if this cooling, as estimated from the last colum of Table 1, is small compared with the convective heat the flame is capable of losing without extinction ( $\emptyset_{\mathrm{H}}{ }^{*}$ ). However this effect of steam can still be included in Eq. 2 and 3 if $\varnothing$ and $\mathrm{H}$ are both reduced to take account of the presence of the steam and $\mathrm{m}^{\prime \prime}$ is regarded as including $\dot{\mathrm{m}}^{\prime \prime}$ "WV

A very similar set of concepts including the use of equation 3 has been used by Tamanini to account for the flow rate of water needed to extinguish wooden slabs burning on both sides (21). Tamanini focussed on the water requirement needed to reduce the adiabatic temperature of the limit flame to $1300^{\circ} \mathrm{C}$. This implies the use of a value of $\phi$ of about 0.45 prior to its modification by steam that accompanies the fuel vapour.

By associating the $\varnothing$ factor of convective cooling of the flame at the fire point to the cooling of the reaction zone associated with flamable limits (18), it is possible to extend the use of equation 2 to a wider range of ambient temperatures, fuel chemistry and oxygen concentrations. However certain assumptions inherent in equation 3 will cease to operate for high values of $\varnothing$ which may be associated with high oxygen concentration, particularly when it is to be expected that there will be significant amounts of unburned oxygen at the surface when the fire point condition is approached.

The heat removal factor by extinguishant $S$ is but one of a number of factors in equations 1 and 2. The fire will be expected to go out on its own if the heat balance is such as to cause the fuel to be cooled to below the fire point. Although a continuous flashing fire regime in which flames cover only part of the surface at any given moment is more likely to become apparent in the absence of a spray, a heat balance which causes a fire to cool through the fire point is unlikely to allow it to survive long in the flashing regime. It should also be mentioned in passing that because of the way the buoyant rising column of flame and hot gases dominate the aerodynamic conditions near the fuel surface, the value of the heat transfer coefficient $h$ that needs to be used in applying equations 2 and 3 to upward and downward facing surfaces is the reverse of values appropriate to normal heat transfer calculations.

The above treatment separates processes of heat transfer in the flame leading to flame extinction, and in the fuel leading to extinction by cooling to the fire point. This of course is major simplification. A general approach to extinction would require the combination of both aspects: This is particularly important if the intention is to predict extinction time rather than critical flow rates. An attempt to do this for open forest fires has been made by Corlett and Williams (22), although they were concerned rather with the breakdown of flame coherence of large areas of fire. This 
they related to the combined effect of heat loss in the flames and the reduced fuel input into the flames caused by application of extinguishant.

\section{FULL SCALE FIRE TESTS}

While over the ages tests may well have been carried out to indicate how much water may be needed for fire extinction, no systematic published information on experimental work has been available until comparatively recently. However the practice has certainly now developed of carrying out large scale tests to give realistic answers to practical problems. Attention, for the most part, has focussed on flow rate and quantities of water needed. for specific types of fire, with specific types of nozzle. In general the practical difficulties in full scale work has precluded obtaining the extensive information on the properties of jets, sprays and fires listed earlier, necessary for fundamental appraisal of the effects of water on the fire.

Protective Installations - Solid Fires. Sprinkler systems were introduced more than a century ago. The water flow rates needed for these systems were developed by trial and error in practice, and remained fairly constant at 0.1 gallon $/ \mathrm{ft}^{2} \mathrm{~min}$. or $5 \mathrm{~mm} / \mathrm{minute}$ or $82 \mathrm{~g} / \mathrm{m}^{2} \mathrm{~s}$ flow over all parts of the plan area, until the late fifties. However it then became clear that for many practical situations, substantially larger flow rates were required. This was due in the main to the introduction of new materials, particularly foam plastics, and high storage. These higher flow rates have found expression in FOC and NFPA rules $(23,24)$. The advent particularly of automated high rack storage and the necessity for intermediate rack sprinklers to which these give rise, has prompted extensive research investigations which are continuing at the present time. It is not possible here to summarise this work adequately; much information is available from organisations such as the Fire Research Station in the U.K. and the Factory Mutual Corporation in the U.S.

It is appropriate to comment on one point. Traditionally the general design of a sprinkler was for it to throw about $50-60 \%$ of its water upwards to hit the ceiling, as a ring of water about $1.5 \mathrm{~m}$ diameter. This water then fell to the ground as large drops. The rest of the water from the sprinkler was sprayed outwards. During the $1950^{\prime} \mathrm{s}$ a different design of sprinkler was introduced which became the standard sprinkler in the U.S., which threw all its water outwards and downwards. Tests which for the most part appear to have been carried out with fires situated between the sprinklers showed the new type as significantly superior to the old type (25). However the design never found similar favour in the U.K., the "old type" sprinkler remained the standard while the new type was recognised as the "spray sprinkler". The reason for the old type sprinkler remaining in favour was that the large drops from the ceiling was thought to be able to penetrate flames moving upwards in the region of the sprinkler. Experience on the effectiveness of the sprinklers in practice has not shown either of the types to be markedly superior to the other. In recent years workers at the Factory Mutual Laboratory have designed coarse drop size sprinklers for specific use in situations where there may be a strong up-draft (26).

Protective Installations - Liquid Fires. Water spray systems were introduced for use against high flash point liquid fires in the U.K. in the thirties, particularly for risks like power stations. Flow rates of about $0.4 \mathrm{gal} / \mathrm{ft}^{2} \mathrm{~min}\left(330 \mathrm{~g} / \mathrm{m}^{2} \mathrm{~s}\right)$ of directional spray produced at pressures exceeding 2.7 bar were regarded as necessary for the risks concerned. The question arose in the fifties as to whether a fine spray which was 
distributed around the risk and which could be pulled in by the upward moving flames, could be regarded as a viable altemative. The requirement of the system was that it should bring about certain extinction of fire that might be expected in a power station within one minute of operation. Experiments $(27,28)$ were carried out under semi-open conditions, on pan fires up to $1.2 \mathrm{~m}$ diameter and with a rig of $50 \mathrm{~mm}$ diameter empty tubes down which burning oil (mostly transformer oil) flowed at a rate up to $0.761 / \mathrm{s}$. Extinction of the pan oil fires was found to be by cooling to the fire point and was found to be related to the flow rate and drop size. However with directional sprays at a pressure of 1.7 bar, it was found that stable splash fires were established in spite of the fact that the liquid fuel was cooled to well below the fire point. These fires became extinguished very quickly or reduced to small flames burning at the edge of the metal vessel used when the spray was turned off.

The tube rig experiment was very demanding with regard to water requirements because of the high temperatures which could be reached by the tubes in a very short time $\left(550^{\circ} \mathrm{C}\right.$ in 2 minutes and $700-900^{\circ} \mathrm{C}$ in 4 minutes) and because of the masking of flames behind the tubes and supporting struts. As the temperature of the tubes increased from $100-500^{\circ} \mathrm{C}$, a marked increase was needed in the flow rate to the envelope area of the tube rig from 0.3 to $1 \mathrm{imp}$. gal. $/ \mathrm{ft}^{2} \mathrm{~min}\left(250-850 \mathrm{~g} / \mathrm{m}^{2} \mathrm{~s}\right)$ to bring about certain extinction in 45 seconds. However a further increase of tube temperature from $500-900^{\circ} \mathrm{C}$ only required a modest increase from 850 to $980 \mathrm{~g} / \mathrm{m}^{2} \mathrm{~s}$. This suggests that a major difficulty encountered by the water spray was its inability because of film boiling to evaporate efficiently on a hot metal surface, under conditions where oil with a much higher boiling point (about $350^{\circ} \mathrm{C}$ ) could evaporate and produce fuel vapour.

Again the effectiveness was regulated by the amount of water spray which could reach the burning oil on the tubes. The tendency of flames ta draw in fine spray was generally frustrated by the comparatively low flow rates needed actually to reduce flame size, which in its turn would reduce the inward pull of air. An experiment (25) with gasoline fires sprayed upward on metal surfaces showed that fine spray introduced laterally was substantially more effective than sprinklers spraying downwards in reducing temperatures reached by metal in the fire. As at present, extinction of fires of low flash point liquids by plain water is regarded as unreliable and is in any case frowned upon because the production of heavy flammable vapours remain unsupressed. Water sprays are used predominantly for cooling neighbouring risks with this type of fire (29).

Fire in Compartments. A number of workers have carried out investigations on the extinction of fires in compartments by hand held water sprays and jets (30-33) and a theoretical model has been put forward to cover this type of problem (34). In the fifties an extensive series of tests on post flashover fires in a room $18 \mathrm{~m}^{2}$ area were carried out at the U.K. Fire Research Station (30), to explore possible benefits that the use of high pressure sprays may bring to the extinction of fires of this kind. They found that with water sprays at a range of rates of flow of $23-114$ litres $/ \mathrm{min}$. produced at pressures of 5.6-35 bar, there was little significant difference in the amount of water needed to control or extinguish the fire. They also found there was no significant difference when jets were used rather than sprays.

Table 4 gives a summary of conditions and results of tests on compartment fires carried out by different workers. All flow rates used in all tests were capable of extinguishing the fire. In spite of a wide difference in ventilation and consequent rate of burning between the tests, the amount of water used to control the fire and the amount of water evaporated was 
TABLE 4 (part 1) - Extinction tests on room fires. Properties of fires.

\begin{tabular}{|c|c|c|c|c|c|}
\hline $\begin{array}{l}\text { Test origins } \\
\text { and references }\end{array}$ & $\begin{array}{l}\text { Borehamwood } \\
\text { tests (mock } \\
\text { furniture) } \\
\text { Ref. } 31\end{array}$ & $\begin{array}{l}\text { University of } \\
\text { Karlsruhe tests } \\
\text { (wood cribs) } \\
\text { Ref. } 32\end{array}$ & $\begin{array}{l}\text { University of } \\
\text { Karlsruhe tests } \\
\text { (real furniture) } \\
\text { Ref. } 32\end{array}$ & $\begin{array}{l}\text { Salzberg } \\
\text { et al (real } \\
\text { furniture) } \\
\text { Ref. } 33\end{array}$ & $\begin{array}{l}\text { Fire Technology } \\
\text { Laboratory } \\
\text { Finland } \\
\text { Ref. } 34\end{array}$ \\
\hline Room Area $\pi^{2}$ & 18 & 12.8 & 12.8 & 13.4 & 8.6 \\
\hline Dimen- Ht. & 2.8 & 2.8 & 2.8 & 2.4 & 2.4 \\
\hline sions Vol. $\mathrm{m}^{3}$ & 50 & 36 & 36 & 32 & 21 \\
\hline $\begin{array}{l}\text { Ventilation } \\
\text { AV } \mathrm{m}^{5 / 2}\end{array}$ & 7.13 & 1.0 & 1.0 & $4.0+$ door & 2.3 \\
\hline Mass of fue $1 \mathrm{~kg}$. & 360 & 380 & 380 & 300 & $\begin{array}{l}20+\text { walls } \\
E \text { ceiling }\end{array}$ \\
\hline $\begin{array}{l}\text { Surface area } \\
\text { of fuel } \mathrm{m}^{2}\end{array}$ & 67.3 & 112 & 40 & $?$ & 43 \\
\hline $\begin{array}{l}\text { Rate of burning } \\
6.5 \mathrm{~A} \sqrt{ } \mathrm{H} \mathrm{kg} / \mathrm{min}\end{array}$ & 46.4 & 6.5 & 6.5 & 26 & 15 \\
\hline $\begin{array}{l}\text { Actual weight } \\
\text { loss rate after } \\
\text { flashover } \mathrm{kg} / \text { min }\end{array}$ & $72($ approx $)$ & 10.4 & 11.3 & $?$ & $\begin{array}{l}4.5 \mathrm{~kg} \\
15.9 \mathrm{~kg} / \mathrm{min} .\end{array}$ \\
\hline $\begin{array}{l}\text { Rate/unit area } \\
\text { of fuel } \mathrm{g} / \mathrm{m}^{2} \mathrm{~s}\end{array}$ & 17.8 & 1.55 & 4.7 & $?$ & 6.2 \\
\hline $\begin{array}{l}\text { Time to flash- } \\
\text { over min. }\end{array}$ & $5-10$ & $28-35$ & $5-25$ & $?$ & $4-5$ \\
\hline
\end{tabular}

much the same. However extra water was required in the Karlsruhe tests which were carried out under conditions of low ventilation and high preburn time, than in the other series which had high ventilation and low preburn time. This extra water was, in the main, needed to proceed from control to complete extinction and a substantial part of it was not evaporated.

A question concerning the extinction of post-flashover fires in compartments is whether they are extinguished by steam produced by heat transfer between hot gases or hot surfaces and water drops or whether they are extinguished by cooling the fuel. Certainly large quantities of steam are seen to be produced when water is used against a post-flashover fire. However one would expect that if the steam were the mechanism, then extinction would be made more difficult by increasing the vent size and if cooling, by increasing the preburn time. Thomas (35) obtained a significant increase of both critical rate of water application and total water needed for a very small fire $\left(0.13 \mathrm{~m}^{3}\right)$ as ventilation increased. However this was for a condition in which the spray used was fixed in position so that it could not impinge on all fuel surfaces and in any case for flow rates of water (approx. $7 \mathrm{~g} / \mathrm{m}^{2} \mathrm{~s}$ ), substantially in excess of critical flow rates for the fuel used. Thomas however also estimated that as the scale increased, cooling the fuel became more important than the production of steam, mainly because of an increase in volume to surface ratio. This tends to be bourne out by the information in Table 4. In particular the difference between the Borehamwood and Karlsruhe tests suggests that cooling the fuel is the mechanism of extinction. It will be noted in table 4 that the least rate of water used to bring about extinction, not necessarily a critical rate, was about $6 \mathrm{~g} / \mathrm{m}^{2}$ of fuel area per second, which may be compared with a critical 
TABLE 4 (part 2) - Extinction tests on room fires. Water application used and results. J = Jet; $S=$ Spray

\begin{tabular}{|c|c|c|c|c|c|c|c|}
\hline $\begin{array}{l}\text { Test origins } \\
\text { and references }\end{array}$ & $\begin{array}{l}\text { Borehamwood } \\
\text { tests (mock } \\
\text { furniture) } \\
\text { Ref. } 31 \\
\end{array}$ & $\begin{array}{l}\text { University of } \\
\text { Karlsruhe tests } \\
\text { (wood cribs) } \\
\text { Ref. } 32\end{array}$ & \multicolumn{2}{|c|}{$\begin{array}{l}\text { University of } \\
\text { Karlsruhe tests } \\
\text { (real furniture) } \\
\text { Ref. } 32\end{array}$} & $\begin{array}{l}\text { Salzberg } \\
\text { et al (real } \\
\text { furniture) } \\
\text { Ref. } 33\end{array}$ & \multicolumn{2}{|c|}{$\begin{array}{l}\text { Fire Technology } \\
\text { Laboratory } \\
\text { Finland } \\
\text { Ref. } 34\end{array}$} \\
\hline $\begin{array}{l}\text { Flow rate } \\
\text { used } 1 / \text { min }\end{array}$ & $22.7-113.7$ & $50-100$ & 100 & $15-25$ & $25-112$ & $46(\mathrm{~J})$ & $\begin{array}{l}18(5) \\
47(5)\end{array}$ \\
\hline No. of tests & $\begin{array}{l}405 \\
103\end{array}$ & $3(\mathrm{~s})$ & $2(s)$ & $1(s)$ & $17(s)$ & 1 & 2 \\
\hline Pressure bars & $5.6-35$ & 5 and 35 & 5 & 5 & 17 & 2 & \\
\hline $\begin{array}{l}\text { Time after } \\
\text { flashover be- } \\
\text { fore application } \\
\text { of agent min. }\end{array}$ & 2 & 12 & 13 & 11 & $0.5-2$ & $1-2$ & \\
\hline $\begin{array}{l}\text { Amount burnt } \\
\text { prior to } \\
\text { application \% }\end{array}$ & 43 & 43 & & 42 & $?$ & $?$ & \\
\hline $\begin{array}{l}\text { Water used } \\
\text { to control } 1 .\end{array}$ & $32($ mean $)$ & $(25-50 ?)$ & $(50 ?)$ & 12 & $23-58$ & $7-40$ & \\
\hline $\begin{array}{l}\text { Water used to } \\
\text { extinguish } \\
\text { completely } 1 .\end{array}$ & 76 (mean) & 162 & 225 & 152 & $50-80$ & $25-43$ & \\
\hline $\begin{array}{l}\text { Amount col- } \\
\text { lected } 1 \text {. }\end{array}$ & Nominally 0 & 64 & 126 & 50 & $?$ & $?$ & \\
\hline $\begin{array}{l}\text { Amount eva- } \\
\text { porated } 1 .\end{array}$ & $\begin{array}{c}\text { Nominally } \\
76\end{array}$ & 98 & 99 & 102 & $?$ & $?$ & \\
\hline $\begin{array}{l}\text { Min. flow ratel } \\
\text { unit fuel area } \\
\mathrm{g} / \mathrm{m}^{2} \mathrm{~s}\end{array}$ & 5.6 & 7.4 & & 25 & $?$ & 6.9 & \\
\hline
\end{tabular}

rate for large wood crib fires mentioned earlier, of about $4 \mathrm{~g} / \mathrm{m}^{2} \mathrm{~s}$, and a general flow rate of $1.3-3 \mathrm{~g} / \mathrm{m}^{2} \mathrm{~s}$, summarised by Heskestad. It is difficult to be convinced that if a spray is aimed at fuel consisting of furniture any special effect of steam due to enclosure of the fire by the room is present unless flow rates less than about $6 \mathrm{~g} / \mathrm{m}^{2}$ of fuel area per second are used and the fire is controlled in well under one minute.

Experiments with an inert gas generator (36) indicated that to extinguish the flames of a post flashover fire in a room with a $1.3 \mathrm{~m}^{2}$ opening, a flow rate of about $1.6 \mathrm{~m}^{3} / \mathrm{s}$ of partly inerted gas containing $10 \%$ oxygen was required. If this were pure steam this flow rate could be equivalent to $1000 \mathrm{~g} / \mathrm{s}$ or $601 /$ minute of water input. However one could argue that a third of this flow rate would be needed if the inerting capability of the steam, rather than reversal of air ingress at the window, controlled the flame extinction process. Flow rates of 20-601/minute are in line with the range of flow rates used in the tests described in Table 4. One cannot therefore rule out flame extinction by steam formation, since steam can be formed in impingement of spray on any hot surface or in the flames themselves. Indeed in the tests carried out by Salzberg the water was stated as having been applied indirectly. 
Thomas in the U.K. and Labes in the U.S. have carried out statistical. analyses on the amount of water used in fire fighting for a range of fires of plan area $5-60000 \mathrm{~m}^{2}$. Both investigations indicate that the flow rate of water increases in proportion to the perimeter of the fire with approximately one jet in use for every 10 metres. The total amount of water used is proportional to the 1-1.2 power of the fire area. The actual relationships found are as follows:

Thomas(37) $J=0.33 \sqrt{a}, \quad t=3.3 \sqrt{ } a$ (for fires mostly with a>200 $\mathrm{m}^{2}$ )

Labes (analysed by Baldwin) (38) $\quad w=1.24 a^{0.664}, t=1.66 a^{0.554}$

$\mathrm{J}=$ number of jets used

$t=$ time in minutes

$W=$ flow rate of water used $(1 / \mathrm{s})$

$a=$ area of fire $\left(\mathrm{m}^{2}\right)$

The two relationships are reasonably coincident if it is assumed that the flow rate of water/jet is about $500-6001 /$ minute.

For an area of $15 \mathrm{~m}^{2}$ the Labes relationships imply a flow rate of 450 $1 /$ minute and a quantity of water used of about 3,500 litres. These are about 10-20 times greater than flow rates and quantities used for rooms of similar area indicated in Table 4 . This may be because at a post flashover fire, a fire brigade would tend to use a branch with a flow of $500 \mathrm{l} / \mathrm{minute}$ or more, rather than a hose reel jet of order $50 \mathrm{l} / \mathrm{minute}$. Moreover the learning factor is less in a repeated series of controlled experiments on fires of one type, carried out in a short period, than it would be in a variety of different fires stretched over a long period. Thus it was found that trained firemen reduced the water required to extinguish a post flashover room fire by a factor of 2-3, once they learned, after a few tests carried out in 3 days, to vary their techniques so as to stop spraying as soon as large quantities of steam were seen to emerge from windows (39). Fry (40) showed that in $90 \%$ of flres in dwellings less than 450 litres of water was used which is much nearer the quantities shown in Table 4 . However only about $10 \%$ of domestic fires are expected to be post flashover fires.

\section{CONCLUSIONS}

There is an increasing amount of information becoming available on the amounts of water that are needed to extinguish fires of different kinds. There is also the beginnings of a structure becoming apparent on the way these requirements may be estimated from a fundamental basis. As in many other areas of fire research this embryonic structure is capable of massive improvement. However it is difficult to see how this can be done without much more experimental work aimed at improving our understanding of the phenomena involved, and checking on the applicability of the structure outlined rather than providing empirical ad-hoc information for presssing practical problems. Of course we need the latter as well but perhaps we can assume that funds for this type of investigation will always be available if an urgent need arises.

Our knowledge of the capability of water sprays to extinguish flames can be improved by measuring the effects of sprays on different flames from both gases and volatile liquids burning at a range of intensities in different turbulent regimes. Investigations should at least cover turbulence 
that might be produced by wind and projected sprays themselves both with and without obstacles being present. Quantification of extinction by cooling could be helped by obtaining more information on the component items in equation 2. One item here still in need of major improvement is the heat of gasification of woods of all kinds with different moisture content. It is desirable also to explore to what extent experiments on pilot ignition may be invoked to give information on both $\phi$ and $\dot{m}^{\prime \prime}$ and how they are related (19). Williams has stressed the importance of the Damkohler number in the extinction process (41). This number which is essentially the ratio of the time that is needed for the flame reaction to the time that is available, is embedded in the various heat loss parameters for flame extinction, including $\emptyset$, that have been used here. The time available for reaction depends on aerodynamic conditions and indeed $\varnothing$ must be reduced almost to zero in a situation where a volatile liquid fire is blown out by air without extinguishing agent added. However blow out velocities are quite large for fires of practical size and they increase with fire dimension. This aspect of the effect of wind is therefore unlikely to be of major practical importance except perhaps in the extinction of solid fuel sticks in a high wind. Nevertheless it is very desirable to integrate this aspect of extinction with those dealt in this paper, since blowout experiments provide a neat method of defining the kinetics of the combustion chemistry. This can be exploited to obtain estimates of $\phi$, and to explore how $\varnothing$ might vary with such variations of aerodynamic conditions that occur in practice, particularly fuel dimensions and air velocity.

Sibulkin (42) has used finite chemistry based on William's experiment to estimate fuel flow rates at extinction of a vertical slab of PMMA burning under laminar conditions at different oxygen concentrations and external radiation. His results are similar to those that may be predicted using equations 2 and 3 . Other calculations by Sibulkin (43) also indicated that reaction kinetics over the relevant range that leads to extinction did not influence the burning rate greatly nor, for a mass fraction of oxygen of 0.18 , did it indicate the presence of oxygen at or near the fuel surface. This gives support to the use of equation 3 to cover conditions at the fire point, albeit at oxygen concentration of 0.236 .

There are also certain other aspects of quantification of the extinction process which have hardly been touched upon. Estimation of extinction time is important, particularly for extinction by fuel cooling. Extinction of glowing may be more difficult than the suppression of flaming of solids and needs to be integrated into a quantitative approach. The conditions which can give rise to enhancement of fire by splashing or sputtering and the way this may seriously affect extinction by cooling the fuel has not yet been addressed. This is likely to be a highly complicated question to sort out quantitatively.

Finally wherein lies the road for improvement of fire fighting practice with water? There appears to be some gap - a factor of about 10-20 between what is needed and what is actually used and the reason for this would repay study. There is a degree of incompatibility between the necessity of delivering as high a fraction as possible of the water that is projected from a nozzle into a fire space, yet once there for the water to be dispersed so that it can reach all surfaces of the burning fuel. The task of harmonizing these two requirements could also repay research. There could be circumstances which could be pinpointed where the production of steam other than by cooling the burning fuel could be beneficial, for example, in extinguishing a fire in the upper part of a high room which has become masked by smoke and where steam formed would remain in place or when the burning fuel is particularly inacessible. However it would be essential to 
follow up by cooling the fuel to avoid the risk of flashbacks and even explosions once the steam formed has been diluted sufficiently with air. For volatile liquid fires in the open this risk is still present and although it is probably practicable to devise sprays which could extinguish flames of moderate size, their use would be limited. Extinction of large gas jet flames with water spray is less likely to suffer from this disadvantage because after extinction the jet tends to dilute itself in the atmosphere to below the limit by turbulent mixing. It is interesting to note there has been encouraging activity in this area (44).

\section{REFERENCES}

1. Theobald, C.R., "The Design of a General Purpose Fire-Fighting Jet and Spray Branch, "Fire Safety Journal, 7: 2, 177-190, 1984.

2. Thomas, P.H. and Smart, P.M.T., "The Throw of water Sprays", Fire Research Note 168, 1955, Fire Research Station, Borehamwood, Herts., U.K.

3. Rasbash, D.J., "The Production of Water Spray of Uniform Drop Size by a Battery of Hypodermic Needles", Journal of Scientific Instruments 30 , $189-192,1953$.

4. Rasbash, D.J., Rogowski, Z.W. and Stark, G.W.V., "Mechanisms of Extinction of Liquid Fires with Water Sprays", Combustion and Flame 4, $223-334,1960$.

5. Rasbash, D.J., Rogowski, Z.W. and Stark, G.W.V., "Properties of Fires of Liquids", Fuel 35, 94-106, 1956.

6. Rasbash, D.J., "The Extinction of Fires by Water Sprays", Fire Research Abstracts and Reviews $4: 1$ and 2, 28-52, 1962.

7. Bryan, J., "The Effect of Chemicals in Water Solution on Fire Extinction", Engineering 159, 457, 1945.

8. Magee, R.S. and Reitz, R.D., "Extinguishment of Radiation Augmented Plastic Fires by Water Sprays", Factory Mutual Research Technical Report FMRC No. 22357-1, 1974.

9. Drysdale, D.D. and Thomson, H.E., University of Edinburgh, Private Communication.

10. Bradrup, J. and Mammergat, Polymer Handbook, 2nd ed., John Wiley 1975.

11. Heskestad, G., "The Role of Water in Suppression of Fire", Fire and Flammability 11, 254-259, 1980.

12. O'Dogherty, M.J., Nash, P., and Young, R.A., "A Study of the Performance of Automatic Sprinkler Systems", Fire Research Technical Paper No. 17 , HMSO, 1967.

13. O'Dogherty, M.J., Young, R.A. and Lange, A., "The Performance of Water-Type Extinguishers on Experimental Class A Fires", Fire Research Note No. 731, 1968, See Ref. 2.

14. Bhagat, B.H., "The Extinguishment of Burning Wood Charcoal Surfaces", Fire Safety Journal 3, 47-53, 1980/81.

15. Rasbash, D.J. and Langford, B., "Burning of Wood in Atmospheres of Reduced Oxygen Concentration", Combustion and Flame 12, 1, 33-40, 1968.

16. Rasbash, D.J., "Heat Transfer Between Water Sprays and Flames of Freely Buming Fires", Proc. Symp. on the Interaction Between Fluids and Particles, I.Chem. E., 217, 1962 .

17. Rasbash, D.J., "Relevance of Fire Point Theory to the Assessment of Fire Behaviour of Combustible Materials", University of Edinburgh, 169, 1975.

18. Rasbash, D.J., "Theory in the Evaluation of Fire Properties of Combustible Vaterials", VFDB, 5 th International Fire Protection Seminar, Karlsruhe, 113, 1976. 
19. Rasbash, D.J., Drysdale, D.D. and Deepak, D., "Critical Heat and Mass Transfer at Pilot Ignition and Extinction of a Material", The American Soc. of Mech. Eng. Symposium, Boston, 1983.

20. Spalding, D.B., Some Fundamentals of Combustion, Gas Turbine series, ed. J. Hodge, pp 62,63,126, Butterworth Scientific Publications, 1955, London.

21. Tamanini, F., "A Study of the Extinguishment of Vertical Wood Slabs in Self-Sustained Burning by Water Spray Application", Combustion Science and Technology $14,1-15,1975$.

22. Corlett, R.C. and Williams, F.A., "Modeliing Direct suppression of Open Fires", Fire Research 1, 6, 323-337, 1979.

23. Rules for Automatic Sprinkler Installations, 29th ed., F.0.C. London, 1968.

24. NFPA: National Fire Codes, No. 13, 1973.

25. Thompson, N.J., Fire Behaviour and Sprinklers, NFPA, 1964.

26. Dundas, P.H., "Cooling and Penetration Study", FMRC Serial No. 18792. May 1974 .

27. Rasbash, D.J. and Rogowski, Z.W., "Extinction of Fires in Liquids by Cooling with Water Sprays", Combustion and Flame 1, 4, 453-466, 1957.

28. Rasbash, D.J. and Stark, G.W.V., "Extinction of Running Oil Fires", The Engineer, 862, 1959.

29. NFPA, National Fire Codes, No. 15, 1982.

30. Hird, D., Pickard, R.W., Fittes, D.W. and Nash, P., "The Use of High and Low Pressure Water Sprays against Fully Developed Room Fires", Fire Research Note 388, 1959, See Ref. 2.

31. Fuchs, P., "Arbeitsgemeinschaft Feuerschutz", (AGF), Berichte 29, University of Karlsruhe, 1975.

32. Salzberg, F. Vodvarka, F.J. and Maatman, G.I., "Minimum Water Requirements for Suppression of Room Fires", Fire Technology 6, 22, 1970.

33. Kokkala, M., "Extinguishment of Compartment Fires using Portable Chemical Extinguishers and Water", Fire Technology Laboratory, Finland, private communication 1985.

34. Bal1, J.A. and Pietrzak, L.M., Fire Research 1, 291, 1979.

35. Thomas, P.H. and Smart, P.M.T., "The Extinction of Fires in Enclosed Spaces", Fire Research Note 86, 1954, see Ref. 2.

36. Stark, G.W.V. and Card, J.F., "Control of Fires in Large Spaces with Inert Gas and Foam Produced by a Turbo-Jet Engine", Fire Research Note no. 550, 1964, see Ref. 2 .

37. Thomas, P.H., "Use of Water in the Extinction of Large Fires", Quart. Instn. Fire Engineers 19, 35, 130-132, 1959.

38. Baldwin, R., "Use of Water in the Extinction of Fires by Brigades", Instn. Fire Engineers Q. 31, 82, 163-168, 1971.

39. Thomas, P.H. and Smart, P.M.T., "Fire Extinction Tests in Rooms", Fire Research Note 121, 1954, see Ref. 2.

40. Fry, J. and Lustig, "Water Used in Firefighting", Fire Research Note 492,1963 , see Ref. 2.

41. Williams, F.A., "A Review of Flame Extinction", Fire Safety Journal 3, $2-4,163-175,1981$.

42. Sibulkin, M. and Gale, T., "The Effects of External Radiation on Solid fuel Diffusion Flames", J. Fire Science 2, 70, 1984.

43. Sibulkin, M., Kulkarni, A.K. and Annamalai, K., "Burning on a Vertical Fuel Surface with Finite Chemical Reaction Rate", Combustion and Flame 44, 187-199, 1982 .

44. McCaffrey, "Jet Diffusion Flame Suppression using Water Sprays - an Interim Report", Combustion Science and Technology 40, 107-136, 1984. 


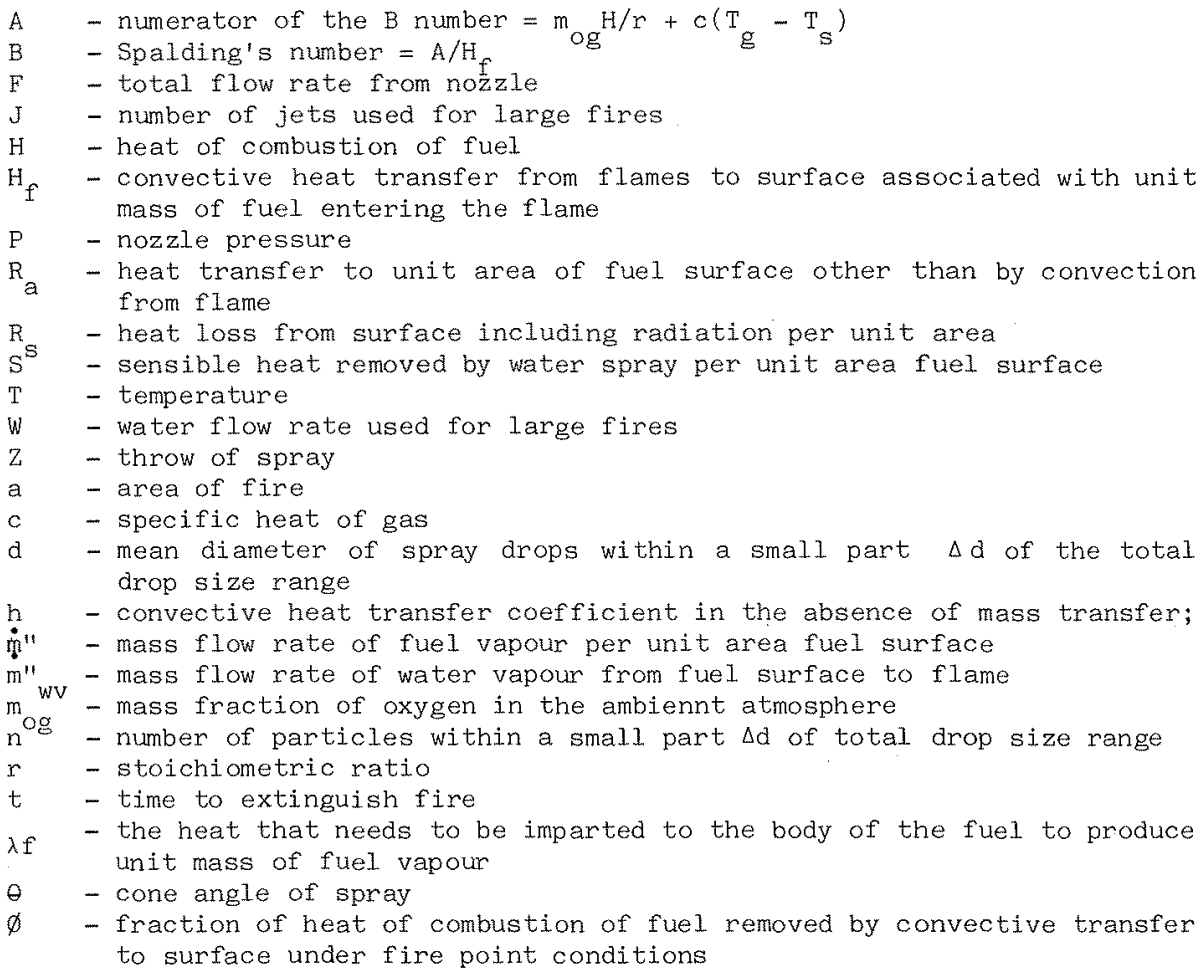

\section{SUBSCRIPTS}

- at the fire point condition

- in the ambient atmosphere

- at the fuel surface. 
